\title{
Microbial Extracellular Polymeric Substances: Production, Isolation and Applications
}

\author{
Tapan Kumar Singha \\ Department of Microbiology, Maharshi Dayanand University, Rohtak-124001
}

\begin{abstract}
s
Microbial polysaccharides have multiple functions and can be divided into intracellular polysaccharides, structural polysaccharides and extracellular polysaccharides or exopolysaccharides (EPS). EPS from both prokaryotes and eukaryotes has a great deal of research interest. Recent approaches are carried out to replace the traditionally used plant gums by their bacterial counterparts. The bacterial EPS represent a huge variety of chemical structures, but have not yet get appreciable significance. Chemically, EPS contains high molecular weight polysaccharides (10-30 kDa) and have homopolymeric as well as heteropolymeric composition. They have new-fangled applications due to their unique properties they possess. Therefore EPS have found multifarious applications in the food, pharmaceutical and other industries. It also possesses potential application on waste water treatment.
\end{abstract}

Keywords- exopolysaccharides (EPS); microorganisms; homopolymeric; Application of EPS; Isolation of EPS

\section{Introduction:}

In recent years, the increased demand for natural polymers or biopolymers for various industrial and biotechnological applications has led to a renewed interest in exopolysaccharides or extracellular polymeric substances (EPS) production by microorganisms as soluble or insoluble polymers. Different types of polysaccharides produced by plants (cellulose, pectin and starch), algae (agar, alginate and carrageenan) and bacteria (alginate, dextran, gellan, pullulan and xanthan gum) are commonly used as food additives for their gelling, stabilizing or thickening properties [1] .EPS produced by both prokaryotes (eubacteria and archaebacteria) and eukaryotes (phytoplankton, fungi, and algae), has a great deal of research interest [3].

EPS are metabolic products that accumulates on the cell surface of bacteria [2]. These are composed of a variety of organic and inorganic substances. Their composition and structure is widely variable: they may be either homopolysaccharide such as dextran, mutans and levans, or heteropolysaccharides. Carbohydrate is the predominant constituent in the EPS of many pure cultures, whereas proteins can be found in substantial quantities in the sludges of many wastewater treatment plants [4-5].

\section{Physiological role of EPS in bacteria}

They can form a protective layer for the cells against the harsh external environmental condition, and also serve as carbon and energy reserves during starvation. It has been demonstrated that EPS plays a wide variety of biological functions including prevention of desiccation, protection from environmental stresses like protection against toxins and antibiotics, adherence to surfaces, pathogenesis and symbiosis [6-7]. These EPS can sequester nutrient materials from the surrounding environment as part of a general microbial strategy for survival under oligotrophic conditions [8-9]. EPS also have the potential to physically prevent access of certain antimicrobial agents by acting as an ion exchanger; there by restricting diffusion of compounds into the biofilm [10]. During the process of colonization on a particular surface, a bacterium overproduces extracellular polymeric substances that help in the formation of biofilm [11]. These polymers, especially EPS are the materials which construct the biofilm matrix, serving as a multipurpose functional element for adhesion, immobilization of cells on the colonized surface, protection, recognition and facilitating spatial arrangement of different species within the biofilm [12].

\section{Source of EPS producing bacteria}

Microorganisms producing EPS are found in various ecological niches. Environment having a medium with high carbon/nitrogen ratio are known to contain microorganisms producing polysaccharides, for example, effluents from the sugar, paper or food industries as well as wastewater plants [16].In general, EPS producing bacteria are found in the environment that offers high amount of organic substances

\section{Isolation of EPS producing bacteria}

EPS producing bacteria can be isolated using a complex media or a chemically defined synthetic media. These organisms produce colonies with mucoid or watery surface having glistening and slimy appearance on agar plate can be detected macroscopically [13]. Congo red staining can be used to identify the presence of extracellular polysaccharides (slime) in the microbial EPS [14]. Capsule staining may also be a useful method to identify the presence of capsular EPS on the surface of bacterial strains using crystal violet and 20\% CuSO4 aqueous solution [15] or India ink. 


\section{Microorganisms producing EPS}

There are many microorganisms known to produce EPS that can be found as in capsular material or as dispersed slime in the surrounding environment with no obvious association to any one particular cell [17]. EPS have been isolated from different genera of Archaea, Bacteria, Fungi and Alga mainly belonging to mesophilic, thermophilic and halophilic groups.

Lactic acid bacteria (LAB) are the well-known mesophilic group of EPS producer. Among mesophilic bacteria genera, Bacillus spp., Lactobacillus Bulgaricus, Lactobacillus helveticus, Lactobacillus brevi, Lactococcus lactis, Leuconostoc mesenteroides, and Streptococcus spp are the good EPS producer, lactic acid bacteria. The other potential EPS producers are Pseudomonas spp. Acetobacter spp. Aureobasidium spp. Sinorhizobium spp. Escherichia spp. Acetobacter spp.

Thermophilic microorganisms can be found in every phylum of Archaea and Bacteria, and have been isolated from various thermophilic environments: marine hotsprings, both deep and shallow, and terrestrial hot springs that have served as sources for isolation of microbial EPS producers. Among the thermophilic archaeal genera, Thermococcus and Sulfolobus produce EPS, and Archaeoglobus fulgidus and Thermococcus litoralis accumulate significant amounts of EPS as biofilms [18-20]. Not only archaea, several thermophilic bacteria are also good producers of large amounts of EPS such as Bacillus thermantarcticus, Geobacillus thermodenitrificans, and Bacillus licheniformis, isolated from hot marine shallow vents, or as extremely thermophilic fermentative anaerobe. The co-cultures of Thermotoga maritima, Thermotoga maritima and the H2consuming methanogen Methanococcus jannaschii, that were found to develop significant biofilms, or finally as Geobacillus tepidamans V264, isolated from a terrestrial hot spring, that is able to produce an unusually thermostable EPS that starts to decompose at about $280^{\circ}[21]$.

Many halophilic Archaea were described as being EPS producers such as Haloferax, Haloarcula, Halococcus, Natronococcus, and Halobacterium [22-25]. The most common halophilic EPS producers are bacteria belonging to the genus Halomonas, most importantly $H$. maura, H. eurihalina, $H$. ventosae, and $H$. anticariensis. EPS synthesized by Halomonas strains unusually consists of high sulphate content and a significant amount of uronic acids determining their good gelifying properties [26].

\section{Production of EPS}

EPS production can be influenced by bacterial growth phase, medium composition (carbon source nitrogen source), $\mathrm{pH}$ and temperature [27-28]. The biosynthesis of EPS is related to the primary carbohydrate metabolism of the producing cells [29, 27and 30]. In general EPS production is expected to take place during active sugar consumption, as it requires large numbers of activated nucleotide sugars, energy for building the repeating units, for polymerization and transmembrane translocation. It has been reported that EPS is a growth-associated product. Several factors influence growth and EPS production, in particular medium composition [27and 31]: the presence of casein hydrolysate [32], co-cultures [33] and the amount of glucose [34].There are some vital limitation factors like, Carbon $(\mathrm{C})$, nitrogen $(\mathrm{N})$, phosphate $(\mathrm{P})$ and oxygen $(\mathrm{O})$ that effect the conversion of the carbon source into polysaccharides the exopolysaccharides production is favored by a high carbon/nitrogen ratio, where 10:1 is considered to be the most favorable for maximal EPS production [16].

\section{Extraction of EPS and Purification}

Extraction of EPS having as slime: "Slime" EPS maybe isolated from microorganisms by centrifugation. The speed and time of centrifugation depend on the nature and viscosity of the polysaccharide. When working at the laboratory scale, ultracentrifugation may be used to remove most of the cells or their debris from the culture broth containing polysaccharides [16]. When the EPS is thermally stable, heat treatment can be used to improve the separation of microorganisms from the broth. Instead lowering the viscosity, heat treatment partially kills the cells through pasteurization and also inactivates some of the enzymes present in the broth. Heat treatment enhances the viscosity in case of xanthan, though this effect is pH dependent [35]. Extraction of EPS having as a capsule: "Capsular" EPS must be dissociated first from the cells. The selection of purification or separation method depends on the nature of the association between the cells and the polysaccharides. Normally centrifugation enables the separation of weakly associated capsular EPS. As the capsular EPS is tightly associated with the cells, more severe conditions, such as alkaline treatment (e.g. with sodium hydroxide), prior to centrifugation and alcohol precipitation are needed [16].

The other methods include boiling the cell suspension for $15 \mathrm{~min}$ in hot water, heating at $60{ }^{\circ} \mathrm{C}$ in saline solution, heating in a mixture of phenol water at $65^{\circ} \mathrm{C}$ or sonicating the cell suspension. Autoclaving is another most frequently used treatment for releasing capsular polysaccharides from cells, but this may cause cell disruption and decrease in broth viscosity.

\section{Potential application of EPS}

There is a great deal of interest in the EPS produced by microorganisms used in the food, pharmaceutical, biomedical, bioremediation, waste water treatment and bioleaching fields due to their wide chemical, structural diversity and their physical, rheological and other unique properties [36,37]. 


\subsection{Application in food and health aspects 8.1.1 EPS in food applications}

EPS may function as viscosifying agents, stabilizers, emulsifiers, gelling agents, or water-binding agents in food [38]. Large number of polysaccharides used in foods is of plant origin. Most of them are chemically or enzymatically modified in order to improve their rheological properties, e.g. cellulose, starch, pectin, alginate and carrageenan. EPS produced by microorganism have unique rheological properties because of their capability of forming very viscous solutions at low concentrations and their pseudoplastic nature [39]. Dextran is the first industrial polysaccharide produced by lactic acid bacteria. Due to their structural differences, some dextrans are water soluble and others are insoluble. Dextran may be used in confectionary to improve moisture retention, viscosity and inhibit sugar crystallization. In gum and jelly candies it acts as gelling agents. In ice cream it inhibits crystal formation, and in pudding mixes it provides the desirable body and mouth feel [40].

\subsubsection{Antimicrobial compounds as natural food preservative}

Most of the foods deteriorate during storage. In addition to physical, chemical and enzymatic factors that alter the sensory characteristics, the microbiological changes in foods may bring about a wide range of spoilage reactions, including food poisoning [41]. So, it is very important to inhibit the growth of spoilage microorganisms in foods. Due to a strong demand for natural and minimally processed foods, there has been a growing interest in the use of antimicrobial compounds produced by $\mathrm{LAB}$ as a safe and natural way of food preservation. In addition to nisin which is widely used in foods [42], another antimicrobial compound that has been proposed for use in food preservation is reuterin produced by L. reuteri [43]

\subsubsection{Health aspects}

In recent year there is an increasing demand of using of lactic acid bacteria as probiotics. The important feature for a LAB strain to be a probiotics are, in addition to acid and bile tolerance, the ability to produce antimicrobial compounds against pathogenic and cariogenic bacteria, and to adhere and colonize human intestinal mucosa [44]. The antimicrobial compound production may be beneficial to the colonization of probiotics in gut mucosa by increasing their competitive advantage against normal gastrointestinal microflora [45]. It has been shown that capsular polysaccharide might promote the adherence of bacteria to biological surfaces, thereby facilitating the colonization of various ecological niches [46]. The EPS had been found to be present in adherent biofilms [47]; the EPS might function as initial adhesion and permanent adhesion compounds [48].

\subsection{Biomedical application}

Antitumor, antiviral and immune stimulant activities of polysaccharides of marine Vibrio and Pseudomonas have been reported [49]. A low molecular weight heparin-like EPS having anticoagulant property has been isolated from Alteromonas infernus, obtained from deep-sea hydrothermal vents [50 and 51]. Clavan, an L-fucose containing polysaccharide has a potential role in preventing tumor cell colonization of the lung, in regulating the formation of white blood cells, in the treatment of the rheumatoid arthritis, in the synthesis of antigens for antibody production and in cosmeceuticals as skin moisturizing agent [52].

\subsection{Emulsifiers}

Surfactants and emulsifiers from bacterial sources create an attention because of their biodegradability and possible production from renewable resources. Emulsan by Acinetobacter calcoaceticus RAG-1 has been commercialized [53]. This polysaccharide stabilized emulsan more effectively than other commercial gums such as arabic, tragacanth, karaya and xanthan [54]. Apart from this emulsion, an EPS produced by a marine bacteria, is reported to form stable emulsions with a number of hydrocarbons. This EPS had been proved it is more efficient than the commercially available emulsifiers [55].

\subsection{Bioremediation and waste water treatment}

An expanding area of biotechnology is the application of EPS producing microorganisms in the remediation of environmental effluents produced by the mining [55-58]. Biofilm-mediated bioremediation has been found to be a more effective and safer alternative to bioremediation with planktonic bacteria as cells growing within a biofilm have higher chances of adaptation to different environmental condition and their subsequent survival [59-61]. Biofilms maintain optimal chemical and physiological conditions, localized solute concentrations and redox potential, allowing cells to improve mineralization processes [62]. Generally biofilm reactors are used to treat hydrocarbons, heavy metals and large volumes of dilute aqueous solutions such as industrial and municipal waste water [62-63].

The potential role of EPS in the removal of heavy metals from the environment is due to their involvement in flocculation and ability to bind metal ions from solutions [64]. A major group of bacteria commonly found in metal contaminated waste waters are sulfate reducing bacteria (SRB). This group of bacteria has been shown to be highly efficient in anaerobic degradation of many organic pollutants and in the precipitation of heavy metals from waste water [63]. Other bacteria exhibiting biosorption of toxic heavy metals in bioremediation processes include Enterobacter and Pseudomonas species [64] 


\section{Conclusion}

In present scenario the biopolymers already in the market (plant, algal and microbial) appear quite adequate for most applications and industrial demand. Therefore the look for greener technologies will probably augment the use of bacterial exopolysaccharide for industrial applications. Thus, the use of bacteria as renewable resource for the production of biopolymers can be great advantageous. The present knowledge about bacterial EPS suggests that these polymers may cover a broad range of complex chemical structures and consequently different properties. Moreover, it is reasonable to anticipate that exopolysaccharides from newer bacteria would provide ample opportunities for newer industrial avenues and have chattels different from those already available.

\section{References:}

1. W. Sutherland, Novel and established applications of microbial Polysaccharides. Trends Biotechnol. 16, 1998, $41 \pm 46$

2. J. W. Morgan, C. F. Forster, L. M. Evison, A comparative study of the nature of biopolymers extracted from anaerobic and activated smudges. Water Res. 6, 1990, 743-750.

3. A.S. Kumar, K. Mody, B. Jha, Bacterial exopolysaccharides - a perception. Journal of Basic Microbiology, 47, 2007, 103-117.

4. H.H.P. Fang and X.S. Jia, Extraction of extracellular polymer from anaerobic sludges. Biotechnol. Tech. 10 (11), 1996, 803-808

5. M.C. Veiga, K.J Mahendra, W.M. Wu, R.I. Hollingsworth, J.G. Zeikus, 1997. Composition and role of extracellular polymers in methanogenic granules. Appl. Environ. Microbiol. 63 (2), 1997, 403-407

6. C. Whitfield \&M.A. Valvano, Biosynthesis and expression of cell-surface polysaccharides in gram- negative bacteria. Adv. Microb. Physiol. 35, 1993, 135-246.

7. I.S. Roberts, The biochemistry and genetics of capsular polysaccharide production in bacteria. Annu. Rev. Microbiol. 50, 1996, 285-315.

8. G.M. Wolfaardt, J.R. Lawrence, R.D. Robarts, and D.E. Caldwell, In situ characterization of biofilm exopolymers involved in the accumulation of chlorinated organics. Microb. Ecol. 35, 1998, 213-223.

9. A.W. Decho, Microbial biofilms in intertidal systems: an Overview. Cont. Shelf Res. 20, 2000, $1257-1273$.

10. P. Gilbert, J. Das, and I. Foley, Biofilm susceptibility to antimicrobials. Adv. Dent. Res. 11, $1997,160-167$.

11. G.G. Geesey and D.C. White, Determination of bacterial growth and activity at solid-liquid interfaces. Ann. Rev. Microbiol. 44, 1990, 579-602.

12. D.G. Allison, B. Ruiz, C. San Jose, A. Jaspe, and P. Gilbert, Extracellular products as mediators of the formation and detachment of Pseudomonas fluorescence biofilms. FEMS Microbiol. Ecol. 167, 1998, 179184.

13. M. Vescovo, G. L. Scolari, and V. Bottazzi. 1989. Plasmid-encoded ropiness production in Lactobacillus casei spp. casei. Biotechnol. Lett. 10, 1989, 709-712.

14. T.R. Neu, In situ cell and glycoconjugate distribution in river snow studied by confocal laser scanning microscopy. Aquat Microb. Ecol. 21, 2000, 85-95.

15. D. Cain, H. Hanks, M. Weis, C. Bottoms, J. Lawson, Microbiology Laboratory Manual. Collin County Community College District, McKinney, TX. 2009

16. A. Morin, Screening of polysaccharide-producing microorganisms, factors influencing the production and recovery of microbial polysaccharides. In: Polysaccharides -Structural Diversity and Functional Versatility. Dumitriu, S. (Ed.), Marcel Dekker Inc. Publication, New York, pp. 1998, 275-296.

17. I. W. Sutherland, "Biosynthesis of microbial exopolysaccharides," Advances in Microbial Physiology, vol. 23, 1982, pp. 79-150.

18. B. Nicolaus, M. C. Manca, I. Romano, and L. Lama, "Production of an exopolysaccharide from two thermophilic archaea belonging to the genus Sulfolobus," FEMSMicrobiology Letters, vol. 109, no. 2-3, 1993, pp. 203-206.

19. C. Lapaglia and P. L. Hartzell, "Stress-induced production of biofilm in the hyperthermophile Archaeoglobus fulgidus," Applied and Environmental Microbiology, vol. 63, no. 8, 1997, pp. 3158-3163.

20. K. D. Rinker and R. M. Kelly, "Growth physiology of the hyperthermophilic archaeon Thermococcus litoralis: development of a sulfur-free defined medium, characterization of an exopolysaccharide, and evidence of biofilm formation," Applied and Environmental Microbiology, vol. 62, no. 12, 1996, pp. 44784485.

21. M. Kambourova, R.Mandeva, D. Dimova, A. Poli, B.Nicolaus, and G. Tommonaro, "Production and characterization of a microbial glucan, synthesized by Geobacillus tepidamans V264 isolated from Bulgarian hot spring," Carbohydrate Polymers, vol. 77, no. 2, 2009, pp. 338-343.

22. J. Ant 'on, I. Meseguer, and F. Rodr'1guez-Valera, "Production of an extracellular polysaccharide by Haloferax mediterranei," Applied Enviromental Microbiology, vol. 54, no. 10, 1988, pp. 2381-2386. 
23. B. Nicolaus, L. Lama, E. Esposito et al., "Haloarcula spp.able to biosynthesize exo- and endopolymers," Journal of Industrial Microbiology and Biotechnology, vol. 23, no. 6, 1999, pp. 489-496, 1999.

24. N. A. Paramonov, L. A. S. Parolis, H. Parolis, I. F. Bo 'an, J. Ant ' on, and F. Rodr'iguez-Valera, "The structure of the exocellular polysaccharide produced by the Archaeon Haloferax gibbonsii (ATCC 33959)," Carbohydrate Research, vol. 309, no. 1, 1998, pp. 89-94.

25. H. Parolis, L. A. S. Parolis, I. F. Bo' a et al., "The structure of the exopolysaccharide produced by the halophilic Archaeon Haloferax mediterranei strain R4 (ATCC 33500)," Carbohydrate Research, vol. 295, 1996, pp. 147-156.

26. B. Nicolaus, M. Kambourova, and E. T. Oner, "Exopolysaccharides from extremophiles: from fundamentals to biotechnology," Environmental Technology, vol. 31, no. 10, 2010, pp. 11451158.

27. L. De Vuyst \&B. Degeest, Heteropolysaccharides from lactic acid bacteria. FEMS Microbiol. Rev. 23: 1999, $153-177$.

28. S. Petry, S. Furlan, MJ. Crepeau, J. Cerning \& M. Desmazeaud, Factors affecting exocellular polysaccharide production by Lactobacillus delbrueckii subsp. bulgaricus grown in a chemically defined medium. Appl. Environ. Microbiol. 66, 2000, 3427-3431.

29. A. Escalante, C. Wacher-Rodarte, M. Garcia-Garibay \& A. Farrés, Enzymes involved in carbohydrate metabolism and their role on exopolysaccharide production in Streptococcus thermophilus. J. Appl. Microbiol. 84, 1998, 108-114.

30. F. Levander, M. Svensson\& P. Radstrom, Enhanced exopolysaccharide production by metabolic engineering of Streptococcus thermophilus. Appl. Environ. Microbiol. 68, 2002, 784-790.

31. P. Duboc \&B. Mollet (2001) Applications of exopolysaccharides in the dairy industry. Int. Dairy J. 11, 2001, 759-768.

32. J. Cerning, C. Bouillanne, MJ. Desmazeaud\& M. Landon, Isolation and characterization of exocellular polysaccharide produced by Lactobacillus bulgaricus. Biotechnol. Lett. 8, 1986, 625-628.

33. J. Cerning, C. Bouillanne, M. Landon\& MJ. Desmazeaud, Comparison of exocellular polysaccharide production by thermophilic acid bacteria. Science des Aliments 10, 1990, 443-451.

34. J. Cerning, CMGC. Renard, JF. Thibault, C. Bouillanne, M. Landon, MJ. Desmazeaud\& L. Topisirovic, Carbon source requirements for exopolysaccharide production by Lactobacillus casei CG11 and partial structure analysis of the polymer. Appl. Environ. Microbiol. 60, 1994, 3914-3919.

35. I. W. Sutherland, Biotechnology of microbial exopolysaccharides. In: Cambridge Studies in Biotechnology 9. Cambridge University Press, Cambridge, 1990, pp. 1-163.

36. A. M. Fialho, L. M. Moreira, A. T. Granja, A. O. Popescu, K. Hoffmann, I. Sá-Correia, Occurrence, production, and applications of gellan: current state and perspectives. Appl. Microbiol. Biotechnol. $2008,79$.

37. B. Rehm, Microbial exopolysaccharides: Variety and potential applications. In Microbial production of biopolymers and polymer precursors: applications and perspectives; Caister Academic: Norfolk, UK, 2009; pp. 229-254.

38. D.J.C. van den Berg, G.W. Robijn, A.C. Janssen, M.L.F. Giuseppin, R. Vreeker, J.P. Kamerling, J.F.G. Vliegenthar, A.M Ledeboer, and T. Verrips, Production of a novel extracellular polysaccharide by Lactobacillus sake 0-1 and characterization of the polysaccharide. Appl. and Environ. Microbiol. 61, 1995, 2840-2844.

39. A. Becker, F. Katzen, A. Pühler, and L. Ielpi, Xanthan gum biosynthesis and application: a biochemical/genetic perspective. Appl. Microbiol. Biotechnol. 50, 1998, 145-152.

40. R. Whistler, and J.R. Daniel, Functions of polysaccharides in foods. In: Food Additives. eds. A.L. Branen, P.M. Davidson, and S. Salminen, 1990, pp. 395-423. Marcel Dekker, Inc., New York.

41. G. W. Gould, Antimicrobial compound. In: Biotechnology and Food Ingredients. eds. I. Goldberg and R. Williams, 1991, pp. 461-483. Van Nostrand Reinhold, New York.

42. M. Qiao, Lantibiotic nisin of Lactococcus lactis: biosythesis, immunity and regulation. Ph.D. Thesis, University of Helsinki, Finland, 1996.

43. S. E. Lindgren and W. J. Dobrogosz, Antagonistic activities of lactic acid bacteria in food and feed fermentations. FEMS Microbiol. Rev. 87, 1996, 149-164.

44. M. Saxelin, Development of dietary probiotics: estimation of optimal Lactobacillus GG concentrations. Ph.D. Thesis, University of Turku, Finland, 1995.

45. S. Salminen, M. A. Deighton, Y. Benno, and S. L. Gorbach, Lactic acid bacteria in health and disease. In: Lactic Acid Bacteria: Microbiology and Functional Aspects, 2nd edition. eds. S. Salminen, and A. von Wright, 1991a, pp. 343-358. Marcel Dekker, Inc., New York.

46. J. W. Costerton, K. J. Cheng, G.G. Geesey, T. I. Ladd, J. C. Nickel, M. Dasgupta, M, and T. J. Marrie, Bacterial biofilms in nature and disease. Annu. Rev. Microbiol. 41, 1987, 435-464.

47. C. Whitfield, Bacterial extracellular polysaccharides. Can. J. Microbiol. 34, 1988, 415-420.

48. D. G. Allison and I. W. Sutherland, The role of exopolysaccharides in adhesion of freshwater bacteria. J. Gen. Microbiol. 133, 1987, 1319-1327. 
49. K. Okutani, Antitumor and immunostimulant activities of polysaccharides produced by a marine bacterium of the genus Vibrio. Bull. Jap. Soc. Sci. Fish., 50, 1984, 1035-1037.

50. K. Okutani, Antiviral activities of sulfated derivatives of a fucosamine-containing polysaccharide of marine bacterial origin. Nippon Suisan Gakk., 58, 1992, 927-930.

51. J.S. Colliec, L. Chevolot, D. Helley, J. Ratiskol, A. Bros, C. Sinquin, O. Roger, and A. M. Fischer, Characterization, chemical modifications and in vitro anticoagulant properties of an exopolysaccharide produced by Alteromonas infernos. Biochim. Biophys. Acta, 1528 (2-3), 2001, 141-151.

52. P. T. Vanhooren, and E. J. Vandamme, Microbial production of clavan, an L-fucose rich exopolysaccharide. In: Food Biotechnology (S. Bielecki, J. Trampe, and J. Polak, eds.), 2000, pp. 109-114. Elsevier Science B.V., Amsterdam, The Netherlands.

53. E. Rosenberg, A. Zuckerberg, C. Rubinovitz, and D. L. Gutnick, 1979. Emulsifier of ArthrobacterRAG-1: Isolation and Emulsifying properties. Appl. Environ. Microbiol.37, 1979, 402- 408.

54. A.A. Ashtaputre, and A.K. Shah, Emulsifying property of a viscous exopoysaccharide from Sphingomonas paucimobilis. World J. Microbiol. Biotechnol.11, 1995, 219-222.

55. A. Iyer, K. Mody, and B. Jha, Emulsifying properties of a marine bacterial exopolysaccharide. Enzyme Microb. Technol., 38, 2006, 220-222.

56. L. Valenzuela, A. Chi, S. Beard, A. Orell, N. Guiliani, J. Shabanowitz, D. F. Hunt, C.A. Jerez, Genomics, metagenomics and proteomics in biomining microorganisms. Biotechnol. Adv.2006, 24, 197-211.

57. D. E. Rawlings, D.B. Johnson, The microbiology of biomining: development and optimization of mineraloxidizing microbial consortia. Microbiology, 2007, 153, 315-324.

58. G.M. Gadd, Microbial influence on metal mobility and application for bioremediation. Geoderma 2004, 122, 109-119.

59. R. M. Donlan, Biofilms: Microbial life on surfaces. Emerging Infect. Dis. 2002, 8, 881-890.

60. J.W. Costerton, Z. Lewandowski, D.E. Caldwell, D.R. Korber, H.M. Lappin-Scott, H.M. Microbial biofilms. Annu. Rev. Microbiol. 1995, 49, 711-745 C. E.

61. Zobell, The effect of solid surfaces upon bacterial activity. J. Bacteriol. 1943, 46, 3956.

62. R. Singh, D. Paul, R. K. Jain, Biofilms: implications in bioremediation. Trends Microbiol. 2006, 14, $389-397$.

63. P. Singh, S. S. Cameotra, Enhancement of metal bioremediation by use of microbial surfactants. Biochem. Biophys. Res. Commun. 2004, 319, 291-297.

64. A. Pal, A.K. Paul, Microbial extracellular polymeric substances: central elements in heavy metal bioremediation. Indian J. Microbiol. 2008, 48, 49-64. 